\title{
Assessment of Juvenile Growth and Yield Relationship Among Dwarf Cashew Types in Ghana
}

\author{
A. M. Dadzie ${ }^{1}$, P. K. K. Adu-Gyamfi ${ }^{1}$, A. Akpertey ${ }^{1}$, A. Ofori ${ }^{1}$, S. Y. Opoku ${ }^{1}$, J. Yeboah ${ }^{1}$, E. G. Akoto ${ }^{1}$, \\ F. K. Padi ${ }^{1} \&$ E. Obeng-Bio ${ }^{2}$ \\ ${ }^{1}$ Cocoa Research Institute of Ghana, Tafo-Akim, Ghana \\ ${ }^{2}$ CSIR-Crops Research Institute, Kumasi, Ghana \\ Correspondence: A. M. Dadzie, Cocoa Research Institute of Ghana (CRIG), P.O. Box 8, Tafo Akim, Ghana. Tel: \\ 233-243-533-560. E-mail: xmusto@yahoo.co.uk
}

Received: July 15, $2020 \quad$ Accepted: August 22, $2020 \quad$ Online Published: September 15, 2020

doi:10.5539/jas.v12n10p116 URL: https://doi.org/10.5539/jas.v12n10p116

The research was financed by African Development Bank and Ghana Cocobod.

\begin{abstract}
Cashew (Anacardium occidentale L.) is an important tropical cash crop cultivated in Ghana. It provides livelihood for about 200,000 people and contributes $6.1 \%$ to Ghana's gross domestic product (GDP). Four Brazilian dwarf accessions were introduced to improve nut yield. Objectives of this study were to (1) assess the agronomic performance of the accessions across two contrasting ecologies, (2) determine environmental influence on juvenile growth, (3) determine the relationship between early vegetative growth and yield and (4) explore heritability and genetic advance for the measured agronomic traits. The experiment was laid out in a randomized complete block design with 3 replications. Results revealed significant $(p<0.05)$ environmental influence on growth and yield of cashew. Transitional savanna agro-ecology is more suitable for cashew growth and development. Crop year, location and crop year $\times$ location interactions also influenced most of the agronomic traits. Early growth characteristics alone were not enough to predict yield. Genotype B2 ranked highest yielding across the agro-ecologies. Moderate to high heritability and genetic advance estimates were observed for nut yield, plant height and girth, an indication of variability among accessions needed for cashew improvement in Ghana.
\end{abstract}

Keywords: cashew, accessions, dwarf, agro-ecology, heritability, genetic variability

\section{Introduction}

Cashew (Anacardium occidentale L.) is an important tropical cash crop that originated from South America and is widely cultivated in the tropics of Africa. Early survey estimated about 3 million households in Africa are involved in cashew cultivation, an average of 3 hectares of farm land (Aliyu \& Awopetu, 2005). Cashew, significantly contributes to the economy and the livelihood of many African farmers (GEPA, 2018). In Ghana, cashew is the second most important non-traditional export commodity cash crop, which employs about 200,000 people (Buadi et al., 2013). It accounted for approximately 6.1\% of the total GDP of the country in 2010 (Osei Akoto, 2010; Wongnaa \& Awunyo-Vitor, 2013).

The crop is diploid $(2 \mathrm{n}=42)$ with 21 set of chromosome pairs (Aliyu \& Awopetu, 2007). It is resilient and thrives on an annual rainfall of $1500 \mathrm{~mm}$ to $2000 \mathrm{~mm}$ (Sys \& Van Ranst, 1993; Adeigbe et al., 2015) and at a temperature range of 25 to $28{ }^{\circ} \mathrm{C}$ (Dendena \& Corsi, 2014). Because of its versatile nature, it is usually intercropped with several food crops, such as yam, cocoyam and maize (Opoku-Ameyaw et al., 2011; Oluyemisi \& Uwagboe, 2017).

In spite of cashew's importance in Ghana, its cultivation is challenged by factors, such as insect pests and diseases, poor soil fertility, non-availability of improved planting materials and a narrow genetic base of current collections in Ghana (Dadzie et al., 2014). Consequently, yields of cashew are relatively low $(2-3 \mathrm{~kg} / \mathrm{tree} / \mathrm{yr})$ compared with yields of 20-40 kg/tree/yr reported in Tanzania, India and elsewhere (Massawe et al., 1999; Dadzie et al., 2014). Poor cashew yields in Ghana are of grave concern to various stakeholders, and according to Dadzie et al. (2014), other factors contributing to the low yields observed in Ghana emanated from the use of 
unselected seeds distributed by missionaries and the government in the 1960s and 1970s for afforestation program which ended up as source of planting materials in most cashew farms.

Because of the low yields, most farmers' clear large acres of forests land for the establishment of large plantations in order to harvest substantial volume of nuts. This practice reduces the forest cover which causes de-forestation. There is therefore, an urgent need to develop improved high-yielding cashew planting materials from diverse germplasm source in order to reduce the pressure on depleting forest cover during the establishment of new cashew plantations.

Availability of a large diverse germplasm base, presents an opportunity for rapid development of improved cashew varieties. Efforts have been made by the Cocoa Research Institute of Ghana, to broaden the genetic base of the crop to enhance the development of superior high-yielding cashew varieties with large nut size and good outturn percentage for farmers in Ghana.

Consequently, germplasm materials were introduced as seed sources from Benin, Tanzania, Mozambique, Nigeria and Brazil across time and established for field evaluation across two major contrasting environments [transitional savanna (Wenchi) and Guinea savanna (Bole)]. A significant amount of information were obtained from majority of the materials evaluated, except the Brazilian germplasm accessions.

In view of this, a comprehensive assessment of the Brazilian germplasm for agronomic characteristics, yield, disease and pests is vital for effective comparison and determination of potential accessions for future breeding activities, as these traits could significantly impact on the already established plant density per hectare and tree architecture when utilized in hybrid development (Padi et al., 2012).

Tree crop evaluation is laborious, time consuming and expensive, hence the reliance on specific juvenile traits that could enhance the, identification, selection and development of high-yielding varieties at early stage in breeding process is paramount in saving breeding cost and time (Akpertey et al., 2017). Studies by Padi et al. (2012) and Ofori et al. (2015) have shown that the rate of vegetative growth during the juvenile phase such as girth increment and flower intensity, could successfully be utilized in predicting potential performance of cocoa genotypes. Genotypes with rapid girth increment at the juvenile phase, coupled with high flower intensity have been reported to yield better compared to slow girth increment genotypes in cocoa (Adomako et al., 2005). It is therefore, important to investigate the effectiveness of early selection for nut yield based on some selected traits in cashew and determine the relationship that exists between early growth patterns of cashew and potential yield. This study sought to (1) assess the agronomic performance of four dwarf Brazilian cashew accessions across two contrasting agro-ecologies in Ghana, (2) determine environmental influence on growth rate, (3) explore the relationship between early vegetative growth parameters and yield, and (4) determine heritability and genetic advance of the agronomic traits.

\section{Materials and Methods}

\subsection{Genetic Materials}

The germplasm used in this study comprised four cashew accessions namely, B1, B2, B3 and B5 which were introductions from Brazil with unknown pedigree. The four were evaluated together with a local control (CRG C3) over a period of eight years for agronomic traits and nut yield across two contrasting agro- ecologies beginning 2006 to 2014.

\subsection{Field Evaluation}

\subsubsection{Experimental Sites}

Seedlings of the four cashew accessions and control were raised in a nursery for six months and planted out in May 2006 at the Cocoa Research Institute of Ghana's substations in Bole $\left(07^{\circ} 45.171^{\prime} \mathrm{N}, 002^{\circ} 05.803^{\prime} \mathrm{W}\right)$ in the Guinea savanna zone and the National Agricultural Research Station at Wenchi $\left(09^{\circ} 00.561^{\prime} \mathrm{N}, 002^{\circ} 32.237^{\prime} \mathrm{W}\right)$ in the transitional savanna zone. The mean annual rainfall and mean daily temperature of Bole were $1087 \mathrm{~mm}$ and $26.1{ }^{\circ} \mathrm{C}$, respectively while that of Wenchi were $1189 \mathrm{~mm}$ and $27.7^{\circ} \mathrm{C}$ (Osei-Amaning, 1996). The soils of Bole research station consist mainly of Ferric Luvisol with pockets of Eutric Regosols and Lithosols (FAO-UNESCO, 1977) while that of Wenchi is Voltaian sandstone.

\subsubsection{Field Design}

The trial was laid out in randomized complete block design with three replicates. Plants were spaced at $10 \mathrm{~m}$ between rows and $10 \mathrm{~m}$ within rows. Each experimental unit consisted of 20 plants per plot which received formation pruning at the initial growth stage and maintenance pruning once a year at maturity after each harvest. Maintenance weeding was carried out as and when necessary. 


\subsection{Data Collection}

\subsubsection{Growth Data}

Data were collected on stem growth $(\mathrm{mm})$, plant height $(\mathrm{m})$, canopy spread (canopy span) $\left(\mathrm{m}^{2}\right)$ and nut yield $(\mathrm{kg} / \mathrm{ha})$ as previously described by Adu-Gyamfi et al. (2019). Stem growth (stem diameter) was measured using electronic calipers at $10 \mathrm{~cm}$ above-ground surface at six monthly intervals after transplanting. Plant height, was measured as distance from ground to top of apical bud at six monthly intervals after transplanting using a meter rule. All growth measurements recorded prior to nut bearing (first thirty months after transplanting) was defined as juvenile stage while data taken afterwards represented matured stage.

G6 to G30 represents periodic measurements of girth at 6 monthly intervals after transplanting while H6 to H42 represents periodic height measurements taken at 6 monthly intervals after transplanting.

Canopy spread was determined by measuring span (canopy diameter) at two different dimensions (north-south and east-west direction) 72 months after transplanting. The mean of radius taken for each plant were computed using the formula $\pi r^{2}$ where, $\pi=3.142$ and $r=$ radius of canopy to estimate canopy area.

\subsubsection{Yield Data}

Yields were recorded on individual tree basis by weighing total nuts harvested per tree. Nuts of same genotypes in a plot were averaged after bulking for each harvest. The average weight $(\mathrm{kg})$ per tree was multiplied by 100 trees to obtain total yield in $\mathrm{kg} / \mathrm{ha}$. Yield data commenced from 2009 to 2014 at the beginning of the first week of October to the last week of February the following year. Recordings of individual tree yield were done daily during the harvesting season.

Yield efficiency was estimated as described by Akpertey et al. (2017) as the ratio of the average cumulative yield from (2009 -2014) to the difference in trunk cross-sectional area at the commencement of yield to conclusion.

Trunk cross-sectional area (TCA) was estimated as:

$$
\mathrm{TCA}=\left(\pi \mathrm{d}^{2}\right) / 4
$$

where, $\mathrm{d}=$ stem diameter and $\pi=3.142$.

\subsection{Determination of Nut Weight}

$$
\text { Yield efficiency }=\frac{\text { Average cumulative yield }}{\mathrm{TCA}=\left(\pi \mathrm{d}^{2}\right) / 4}
$$

The fresh weight of nuts was determined in the field using a weighing scale (Salter Brecknell 235-6S-110 mechanical scale balance), Brecknell, USA. One-kilogram (1 kg) sample of randomly collected nuts from each plot was used for nut analysis, following the protocol described by Masawe (1999), and Aliyu and Awopetu (2005). Mean nut weight of 20 plants was determined by dividing total sample weight of a particular accession by number of nuts in the sample.

\subsection{Statistical Analysis}

Statistical analyses of all measured traits were performed using GenStat statistical package, version 11 (VSN International Ltd, Hemel Hempstead, UK). Variance analysis for each location was performed for each trait. Normality test of data was conducted using residual error graphs, provided in the software to verify homogeneity of variance for all measured traits.

A combined analysis of variance was conducted using best linear unbiased estimates (BLUE) of plot means following the model:

$$
\mathrm{Y}_{\mathrm{ijkl}}=\mathrm{u}+\mathrm{g}_{\mathrm{i}}+\mathrm{p}_{\mathrm{i}}+\mathrm{tk}+(\mathrm{gp})_{\mathrm{ij}}+(\mathrm{gt})_{\mathrm{jk}}+(\mathrm{tp})_{\mathrm{ik}}+(\mathrm{gpt})_{\mathrm{ijk}}+\mathrm{e}_{\mathrm{ijkl}}
$$

Where, $\mathrm{Y}_{\mathrm{ijkl}}$ is the $\mathrm{i}^{\text {th }}$ observation on the $\mathrm{l}^{\text {th }}$ accession in $\mathrm{j}^{\text {th }}$ location in the $\mathrm{k}^{\text {th }}$ year. The first four consecutive terms represent the mean and the main effects of the accessions (genotypes), locations and years. The subsequent three terms represent the first order interactions, while the next terms represent the second order interaction and the micro-environment deviation within locations and years. Location and genotypes were considered as fixed effects while years were random.

\subsubsection{Estimation of Genotypic and Phenotypic Variances}

Estimates of genotypic and phenotypic variances were made using the formula of Johnson et al. (1955). 


$$
\begin{gathered}
\text { Genotypic variance, }\left(\sigma^{2} \mathrm{~g}\right)=\frac{\mathrm{MSG}-\mathrm{MSE}}{\mathrm{rl}} \\
\text { Genotypic } \times \text { location variance, }\left(\sigma^{2} \mathrm{gl}\right)=\frac{\mathrm{MSGL}-\mathrm{MSE}}{\mathrm{r}}
\end{gathered}
$$

where, $\mathrm{MSG}=$ Mean square for genotypes; MSGL $=$ Mean square for genotype $\times$ location interaction; MSE $=$ Mean square for error; $\mathrm{r}=$ Number of replications; $1=$ Number of locations, and

$\sigma^{2} \mathrm{p}=$ Phenotypic variance, $\sigma^{2} \mathrm{p}=\sigma^{2} \mathrm{~g}+\sigma^{2} \mathrm{gl} / 1+\sigma^{2} \mathrm{e} / \mathrm{rl}$, where, $\sigma^{2} \mathrm{~g}=$ Genotypic variance; $\sigma^{2} \mathrm{gl}=$ Genotype $\times$ location variance; $\sigma^{2} \mathrm{e}=$ Error mean square.

Genotypic and phenotypic co-efficient of variation were calculated by the following formula:

$$
\begin{aligned}
& \text { GCV }=\sqrt{\frac{{\frac{\sigma^{2}}{}}^{2} \times 100}{\bar{x}}} \\
& \text { PCV }=\sqrt{\frac{\sigma^{2} \times 100}{\bar{x}}}
\end{aligned}
$$

where, GCV = genotypic coefficient of variation; PCV = phenotypic coefficient of variation; $\sigma^{2} \mathrm{~g}=\mathrm{VG}=$ Genotypic variance; $\sigma^{2} \mathrm{p}=\mathrm{VP}=$ Phenotypic variance; $\overline{\mathrm{x}}=$ Population mean.

Heritability $\left(\mathrm{H}^{2}\right)$ on accession mean basis was estimated and categorized as described by Robinson et al. (1949) as:

where, $\mathrm{H}^{2}$ is the heritability.

$$
\mathrm{H}^{2}=\frac{\mathrm{VG}}{\mathrm{VP}}
$$

The expected Genetic Advance for each trait was estimated using the equation (Falconer, 1989) as follows:

$$
\mathrm{GA}=\mathrm{K} \sqrt{\mathrm{Vp}} \cdot \mathrm{H}^{2}
$$

Where, $\mathrm{K}=1.40$ at $20 \%$ selection intensity for trait; $\mathrm{Vp}=$ Phenotypic variance for trait; $\mathrm{H}^{2}=$ Broad sense heritability of the trait.

Genetic Advance as percentage of mean was calculated as,

$$
\mathrm{GA} \%=\frac{\mathrm{GA}}{\overline{\mathrm{x}}} \times 100
$$

\section{Results}

\subsection{Trends in Girth Increment of Four Accessions Over 30 Months Across Transitional Savanna and Guinea Savanna Zones}

Rate of girth increment for the four accessions and control within the transitional savanna zone (Bole) was uniform and steady for the first 18 months after which different growth rate and pattern was observed for all accessions (Figure 1) At the 30th month, significant differences $(\mathrm{p}<0.05)$ were observed in the rate of growth. Genotype B2 recorded the highest girth expansion while B3 displayed the least increment. It was obvious genotype B5 was very consistent in the growth rate and did not seem affected by variations in the months as seen with other genotypes. The growth pattern of the accessions observed in Wenchi was similar to the pattern reported in Bole except that the initial 18 months of growth was relatively slower, however, a sharp growth was realized afterwards, with genotype B2 being significantly $(\mathrm{p}<0.05)$ different from the rest by recording the highest girth (Figure 2). Genotype B3 continued to lag among the genotypes under the Guinea savanna environment as well. Growth patterns observed under both environments after eighteen (18) months presented differential performance of genotypes which reflects the phenomenon of genotype by environment interaction as genotypic growth were not consistent with the progression of the months. 


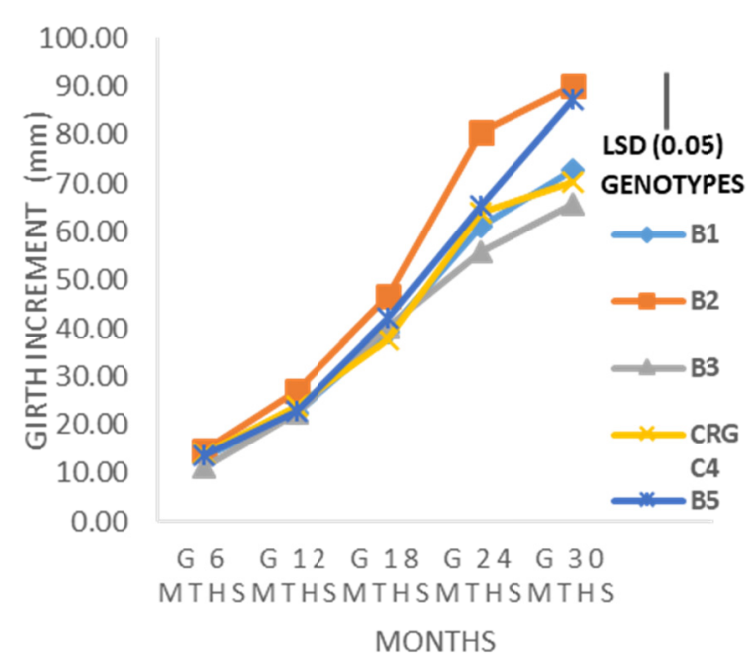

Figure 1. Girth increment over 30 months in Bole

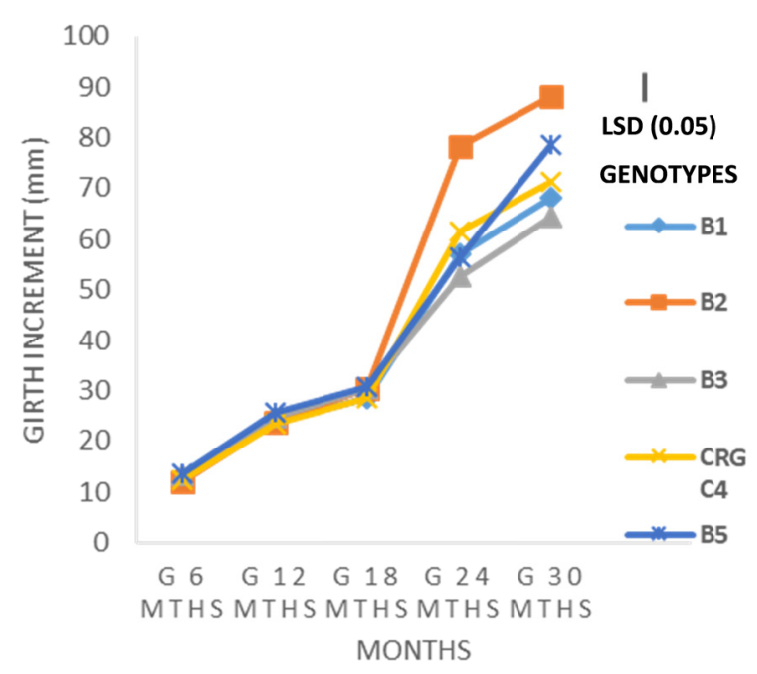

Figure 2. Girth increment across 30 months in Wenchi

\subsection{Trends in Height Increment Observed for Four Accessions and Control Over 42 Months}

The four accessions and control in Bole (Guinea savanna zone) showed relatively similar pattern of growth rate in terms of height increment within the first 24 months (Figure 3). Subsequently, the rate of growth and pattern changed for all the genotypes.

Growth of genotype B5 was significantly $(\mathrm{p}<0.05)$ different from that of B3 and the control (CRG C4). B5 recorded the highest height which implied it was the fastest growing and tallest among the genotypes after 42 months of evaluation. Genotype B3 exhibited the least growth in height among the genotypes. The growth pattern of the accessions after the twenty-fourth (24) month appears to display the effect of genotype by environment interaction. Similar trends were observed for the genotypes under the transitional savanna zone (Wenchi).

In this zone, the fastest growing genotype was B5 while B3 continued to lag significantly $(\mathrm{p}<0.05)$ among the accessions at the forty-second (42) month (Figure 4). Genotypes B1 and B3 consistently lagged behind the control (CRG C4) across the two agro-ecologies, an indication of genotypic influence on rate of height increment. 


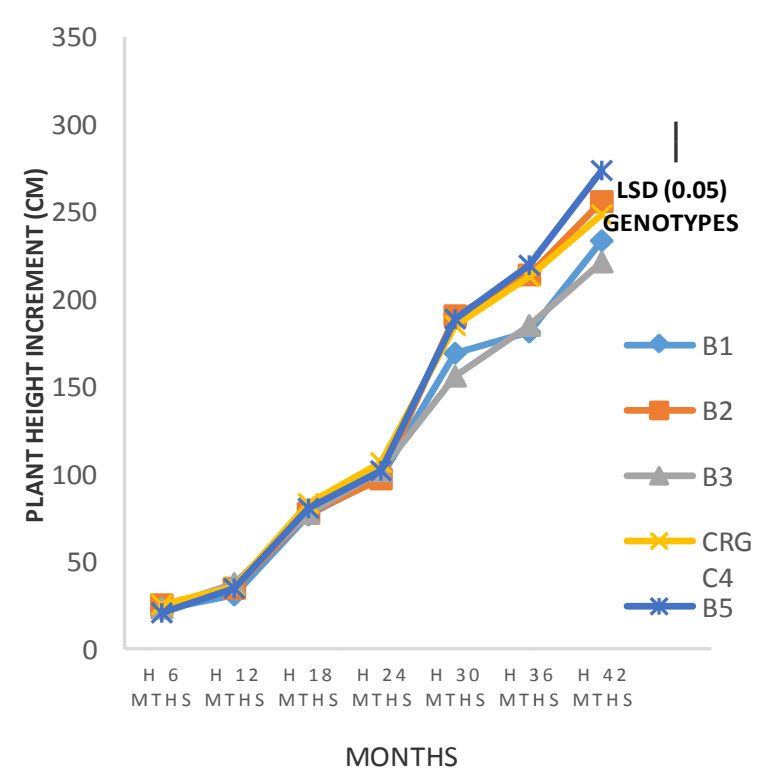

Figure 3. Height increment over 42 months in Bole

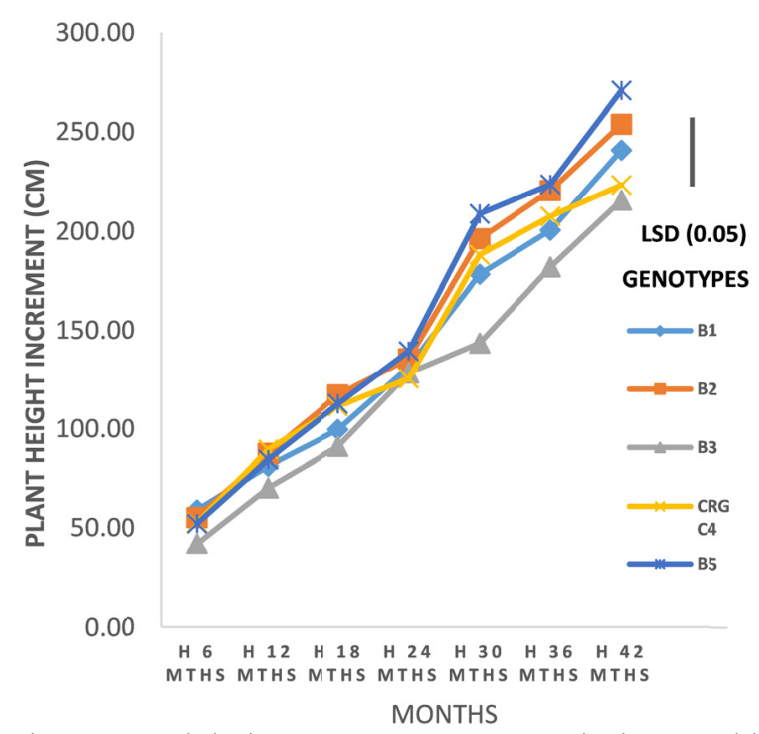

Figure 4. Height increment over 42 months in Wenchi

\subsection{Percent Increment in Growth of Accessions Across the Two Agro-ecologies}

Percentage girth and height increment of accessions across the two agro-ecologies in 30 and 42 months respectively showed relatively fast growth in Wenchi compared to Bole (Figures 5a and 5b).

Percentage increase in girth within 30 months period showed significant $(p<0.05)$ differences in the percentage growth between accession B5 and B3 across the agro-ecologies although the magnitude of growth of the others were comparable within each location irrespective of accession (Figure 5a)

Percentage increase in height for all the accessions were relatively at par at Wenchi compared to Bole (Figure $5 b)$. However, significant $(\mathrm{p}<0.05)$ differences were observed in the percentage growth of accessions B2, B1 and the control CRG C4 across the agro-ecologies (Figure $5 \mathrm{~b}$ ). 


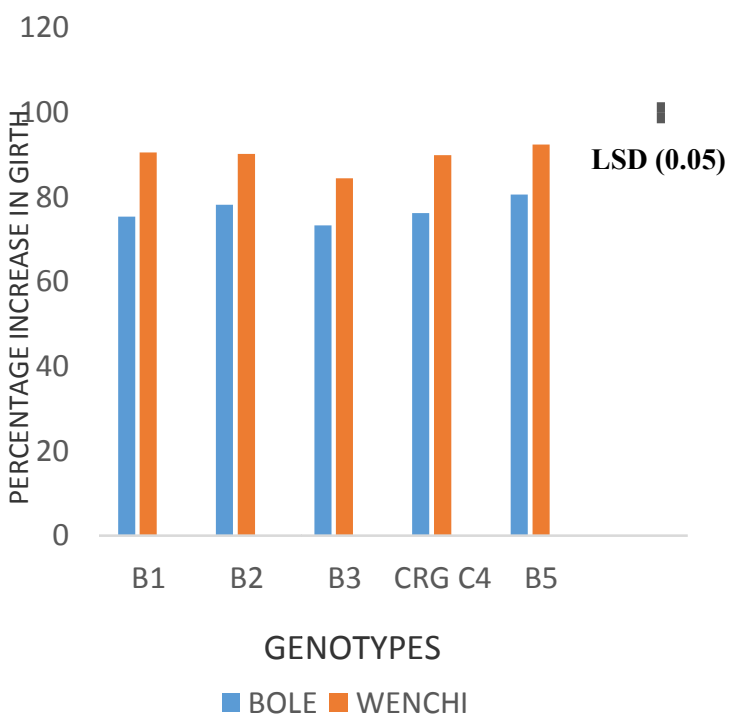

Figure 5a. Percentage increment in girth of accessions two agro ecologies within 30 months

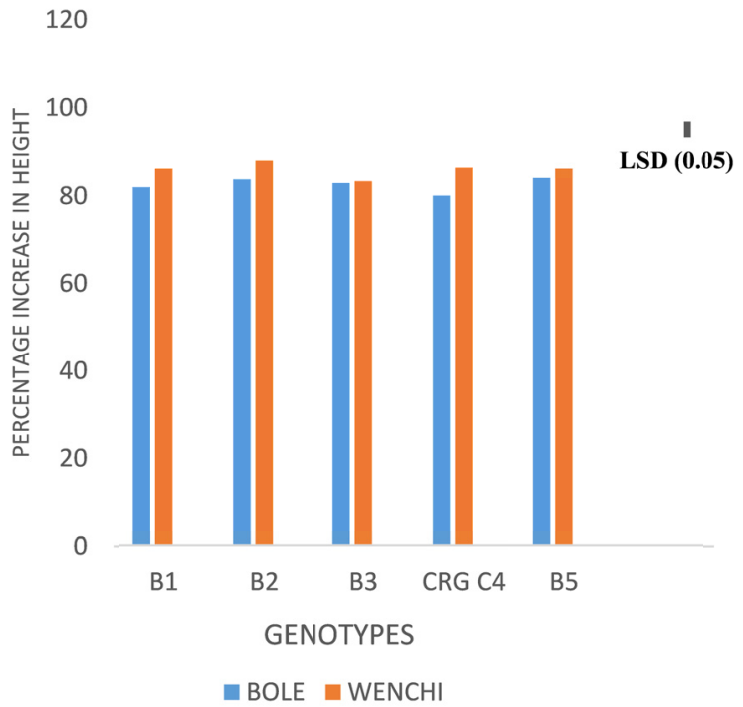

Figure 5b. Percentage increment in height of across accessions across two agro ecologies within 42 months

\subsection{Mean Squares of Yield, Girth and Height Estimated Across the Two Locations}

The analysis of mean squares for nut yield, during the period of bearing revealed significant $(\mathrm{p}<0.05)$ effect of years, location, location $\times$ year interaction and year $\times$ genotype interaction which suggest that crop year and location influence nut yield (Table 1) Furthermore, the significant mean squares for location $\times$ year and year $\times$ genotype interactions indicates the changes in relative performance of the accessions in different locations and years.

Girth and height growth on the other hand were significantly $(p<0.05)$ influenced by all the sources of variation except replication and location $\mathrm{x}$ year $\mathrm{x}$ genotype in the case of height. 
Table 1. Mean squares for yield, girth and height across two contrasting environments (Bole and Wenchi)

\begin{tabular}{lllll}
\hline Source of variation & DF & Yield & Girth & Height \\
\hline Reps & 2 & $0.33 \mathrm{~ns}$ & $13.87^{*}$ & $109.71 \mathrm{~ns}$ \\
Years & 5 & $22.09^{* *}$ & $19074.61^{* * *}$ & $131459.53^{* *}$ \\
Location & 1 & $62.96^{* * *}$ & $2657.20^{* * *}$ & $26728.77^{* * *}$ \\
Location $\times$ Years & 5 & $4.53^{*}$ & $158.18^{*}$ & $2126.65^{* * *}$ \\
Genotype & 4 & $0.50 \mathrm{~ns}$ & $521.16^{* *}$ & $2342.36^{* * *}$ \\
Years $\times$ Genotype & 20 & $1.46^{*}$ & $135.19^{*}$ & $407.89^{*}$ \\
Location $\times$ Genotype & 4 & $0.66 \mathrm{~ns}$ & $23.36^{*}$ & $461.61^{*}$ \\
Location $\times$ Years $\times$ Genotype & 20 & $0.94 \mathrm{~ns}$ & $9.79^{*}$ & $62.911 \mathrm{~ns}$ \\
Error & 118 & 0.62 & 4.10 & 56.5626 \\
\hline
\end{tabular}

Note. ${ }^{*}, * *, * * *$, Significant at $0.05,0.01$ and $\leq 0.001$ probability levels respectively, ns $=$ not significant.

\subsection{Yield Performance of Accessions Across the Guinea Savanna Agro-ecology (Bole)}

Significant $(\mathrm{p}<0.05)$ differences were observed among the accessions for nut yield across the years evaluated in Bole. However, early yields of most accessions were relatively low compared to the yields recorded in the preceding years. Accession B3 appeared to display high-yields during the first year of bearing but displayed alternate bearing the following year. There after the yield appreciated as the years progressed (Table 2). The rest of the accessions including the control (CRG C4) showed steady rise in nut yield as the trees aged.

The average cumulative yields of accession B2 was significantly $(\mathrm{p}<0.05)$ different from that of B3 which recorded the least, although; most of the accessions were not statistically different.

Yield efficiency, which is an indirect measure of assimilate partitioning was significant $(\mathrm{p}<0.05)$ among the accessions, implying that some accessions were moderately vigorous and high yielding while others were not. Accession B3 was observed as most efficient genotype while B5 was the least efficient.

Table 2. Average yields of cashew accessions in Bole (Guinea Savanna)

\begin{tabular}{|c|c|c|c|c|c|c|c|c|}
\hline \multirow{2}{*}{ Genotype } & \multicolumn{6}{|c|}{ Average Yields (kg/ha/yr) } & \multirow{2}{*}{$\begin{array}{l}\text { Avg cum Yld } \\
(\mathrm{kg} / \mathrm{ha} / \mathrm{yr})\end{array}$} & \multirow{2}{*}{$\begin{array}{l}\text { Yield Efficiency } \\
\left(\mathrm{kg} / \mathrm{ha} / \mathrm{cm}^{2}\right)\end{array}$} \\
\hline & Yld 2009 & Yld 2010 & Yld 2011 & Yld 2012 & Yld 2013 & Yld 2014 & & \\
\hline B1 & 137.0 & 183.0 & 323.0 & 346.0 & 420.0 & 561.0 & 237.3 & 8.5 \\
\hline B2 & 129.0 & 170.0 & 310.0 & 343.0 & 481.0 & 554.0 & 250.8 & 5.7 \\
\hline B3 & 246.0 & 134.0 & 274.0 & 292.0 & 374.0 & 480.0 & 212.4 & 9.2 \\
\hline CRG C4 & 118.0 & 156.0 & 296.0 & 312.0 & 413.0 & 533.0 & 217.2 & 8.8 \\
\hline B5 & 114.3 & 139.0 & 279.0 & 323.0 & 467.0 & 530.0 & 230.1 & 5.5 \\
\hline $\operatorname{Lsd}(\mathrm{p}<0.05)$ & 55.0 & 40.0 & 40.0 & 45.0 & 103.0 & ns & 36.5 & 1.7 \\
\hline
\end{tabular}

Note. Avg Cum Yld = Average cumulative yield, ns = not- significant.

\subsection{Yield Performance of Accessions Across the Transitional Savanna Agro-ecology (Wenchi)}

Analysis of nut yield in Wenchi indicated significant $(\mathrm{p}<0.05)$ differences in the performance of the accessions (Table 3). Generally, the initial nut yields were low but increased progressively with time for all the accessions during the study period although some records of alternate bearing were observed for almost all the accessions in most years. Accession B3 appeared promising at the onset of bearing but failed to maintain its rank as best yielding genotype in the third year of nut yield and beyond. Significant $(p<0.05)$ differences in nut yields for the accessions were observed during the years 2009, 2011, 2012, 2013 and 2014, an indication of variability in performance.

However, the average cumulative yields over the study period were not statistically different, although accession B5 was as ranked as highest yielding genotype while B1 was the least. Average yield efficiency estimates showed significant differences $(\mathrm{p}<0.05)$ in the performance of the accession. Accession B3 was identified as most efficient while B2 was relatively the least efficient genotype. 
Table 3. Average yields of cashew accessions in Wenchi (transitional savanna)

\begin{tabular}{|c|c|c|c|c|c|c|c|c|}
\hline \multirow{2}{*}{ Genotype } & \multicolumn{6}{|c|}{ Average Yields (kg/ha/yr) } & \multirow{2}{*}{$\begin{array}{l}\text { Avg Cum Yld } \\
(\mathrm{kg} / \mathrm{ha} / \mathrm{yr})\end{array}$} & \multirow{2}{*}{$\begin{array}{l}\text { Yield efficiency } \\
\left(\mathrm{kg} / \mathrm{ha} / \mathrm{cm}^{2}\right)\end{array}$} \\
\hline & Yld 2009 & Yld 2010 & Yld 2011 & Yld 2012 & Yld 2013 & Yld 2014 & & \\
\hline B1 & 156.0 & 279.7 & 363.3 & 533.3 & 356.0 & 388.0 & 312.1 & 11.5 \\
\hline B2 & 157.0 & 297.0 & 264.7 & 434.7 & 480.7 & 530.7 & 325.0 & 6.8 \\
\hline B3 & 224.3 & 364.3 & 311.0 & 481.0 & 374.0 & 424.0 & 327.0 & 14.6 \\
\hline CRG C4 & 191.7 & 331.7 & 481.3 & 651.3 & 319.7 & 186.0 & 325.3 & 10.9 \\
\hline B5 & 190.7 & 330.7 & 334.3 & 504.3 & 467.0 & 467.0 & 343.3 & 9.5 \\
\hline Lsd $(p<0.05)$ & 81.7 & ns & 199.0 & 196.0 & 121.3 & 250.0 & ns & 2.6 \\
\hline
\end{tabular}

Note. Avg Cum Yld = Average cumulative yield, $\mathrm{ns}=$ not- significant, Yld = yield.

\subsection{A Combined Yield Analysis of Accessions Across Both Guinea Savanna (Bole) and Transitional Savanna (Wenchi) Agro-ecological Zones}

Nut yield in the combined analysis showed a continuous rise as the trees aged. Significant $(\mathrm{p}<0.05)$ differences were found among accessions for nut yield during the year, 2009, 2012 and 2013 (Table 4). However, no differences were noticed in the other years. All accessions seem to demonstrate the alternate bearing phenomenon where nut yield fluctuated with years. The canopy span was relatively similar for all accessions six years after establishment.

The average cumulative yield was not significant $(\mathrm{p}<0.05)$ even though, accession B2 was ranked the highest yielding genotype whilst B3 was the least. Average yield efficiency analysis showed significant differences ( $p<$ 0.05) in efficiency of performance among the accessions. Accession B3 and B1 were the most efficient genotypes whilst B5 and B2 were identified as worst genotypes.

Table 4. Average yields, canopy span and yield efficiency estimate of cashew accessions across (Bole and Wenchi)

\begin{tabular}{|c|c|c|c|c|c|c|c|c|c|}
\hline \multirow{2}{*}{ Genotype } & \multicolumn{6}{|c|}{ Average yields (kg/ha/yr) } & \multirow{2}{*}{$\begin{array}{l}\text { Canopy } \\
\left(\mathrm{M}^{2}\right)\end{array}$} & \multirow{2}{*}{$\begin{array}{l}\text { Avg Cum Yield } \\
(\mathrm{kg} / \mathrm{ha} / \mathrm{yr})\end{array}$} & \multirow{2}{*}{$\begin{array}{l}\text { Yield efficiency } \\
\left(\mathrm{kg} / \mathrm{ha} / \mathrm{cm}^{2}\right)\end{array}$} \\
\hline & Yld 2009 & Yld 2010 & Yld 2011 & Yld 2012 & Yld 2013 & Yld 2014 & & & \\
\hline B1 & 123.5 & 169.5 & 301.3 & 439.7 & 325.5 & 477.0 & 3.2 & 275.1 & 10.0 \\
\hline B2 & 119.3 & 163.5 & 303.5 & 388.7 & 435.7 & 473.7 & 3.3 & 288.0 & 6.3 \\
\hline B3 & 178.0 & 179.3 & 319.3 & 386.5 & 329.0 & 436.7 & 3.1 & 269.7 & 11.8 \\
\hline CRG C4 & 113.8 & 174.0 & 314.0 & 481.7 & 229.5 & 462.8 & 3.4 & 270.9 & 9.9 \\
\hline B5 & 112.2 & 164.7 & 304.7 & 413.5 & 397.0 & 461.3 & 3.3 & 286.8 & 7.5 \\
\hline $\operatorname{Lsd}(p<0.05)$ & 26.0 & $\mathrm{~ns}$ & $\mathrm{~ns}$ & 94.0 & 130.0 & $\mathrm{~ns}$ & $\mathrm{~ns}$ & ns & 1.3 \\
\hline
\end{tabular}

Note. Avg Cum Yld = Average cumulative yield, Yld = yield.

\subsection{Phenotypic Correlation Among Traits}

Analysis of trait correlations revealed a positive but not-significant $(\mathrm{p}>0.05)$ association between Nut yield and traits such as average girth, average height and average canopy span although the magnitude of association varied as $0.21,0.49$ and 0.39 respectively (Table 5).

Table 5. Phenotypic correlations

\begin{tabular}{llll}
\hline & Ave Girth & Ave H & Ave C \\
\hline Average Yield $(\mathrm{r})$ & 0.21 & 0.49 & 0.39 \\
$(\mathrm{P}<0.05)$ & $\mathrm{ns}$ & $\mathrm{ns}$ & $\mathrm{ns}$ \\
\hline
\end{tabular}

Note. $\mathrm{r}=$ correlation co-efficient, $P=$ Probability at $5 \%, \mathrm{~ns}=$ not significant, Ave Girth $=$ Average girth, Ave $\mathrm{H}=$ Average height, Ave $\mathrm{C}=$ Average canopy size.

\subsection{Genetic Component Analysis for Juvenile Girth}

Estimates for genotypic and phenotypic variance of girth in the juvenile phase were low at the onset of the study, it however, increased considerably towards the end of the study (Table 6). Broad-sense heritability estimates were moderate to high according to Robinson et al. (1949). Similar observations were noticed for genetic 
advance as both phenotypic and genotypic coefficient of variation were moderate to high based on the classification of Shivasubramanian and Menon (1973).

Table 6. Genetic analysis of average girth of cashew accessions across Wenchi and Bole

\begin{tabular}{llllll}
\hline \multirow{2}{*}{ Genetic components } & \multicolumn{5}{c}{ Girth } \\
\cline { 2 - 6 } & G 6 MTHS & G 12 MTHS & G 18 MTHS & G 24 MTHS & G 30 MTHS \\
\hline $\mathrm{Vg}$ & 0.82 & 1.17 & 2.85 & 90.19 & 96.58 \\
$\mathrm{Vp}$ & 2.32 & 4.03 & 4.68 & 92.14 & 99.86 \\
$\mathrm{H}^{2}$ & 0.35 & 0.29 & 0.61 & 0.98 & 0.97 \\
Mean & 18.25 & 30.6 & 35.51 & 63.26 & 75.68 \\
Genetic Advance at 20\% & 0.75 & 0.82 & 1.85 & 13.16 & 13.53 \\
Genetic Advance as \% of Mean (20\%) & 4.11 & 2.67 & 5.20 & 20.80 & 17.88 \\
PCV (\%) & 8.34 & 6.56 & 6.09 & 15.17 & 13.20 \\
GCV (\%) & 4.95 & 3.54 & 4.76 & 15.01 & 12.99 \\
\hline
\end{tabular}

Note. $\mathrm{G}=$ Girth, MTHS = Months, $\mathrm{Vg}=$ Genotypic variance, $\mathrm{Vp}=$ Phenotypic variance, $\mathrm{H}^{2}=$ broad sense heritability, $\mathrm{GCV}=$ genotypic coefficient of variation, $\mathrm{PCV}=$ phenotypic coefficient of variation.

\subsection{Genetic Component Analysis for Juvenile Height}

Estimates of phenotypic $(\mathrm{Vp})$ and genotypic $(\mathrm{Vg})$ variance for height during the early growth stage of the accessions were relatively low but increased as the plants appreciated in size (Table 7). Considerable reduction was observed for both $\mathrm{Vp}$ and $\mathrm{Vg}$ during the $24^{\text {th }}$ month although components appreciated significantly in the subsequent months. Broad-sense heritability estimates for height was moderate to high as the plants aged. High heritability estimates suggested potential transfer of traits to off-springs during hybrid development. Estimates for genetic advance using $20 \%$ selection intensity ranged from $0.29 \%$ for the sixth month to $26.53 \%$ for the forty-second month. Estimates of phenotypic and genotypic co-efficient of variation were moderate across the months.

Table 7. Genetic analysis of average height of cashew accessions across two environments (Wenchi \& Bole)

\begin{tabular}{llllllll}
\hline \multirow{2}{*}{ Genetic components } & \multicolumn{7}{c}{ Height } \\
\cline { 2 - 8 } & H 6 MTHS & H 12 MTHS & H 18 MTHS & H 24 MTHS & H 30 MTHS & H 36 MTHS & H 42 MTHS \\
\hline $\mathrm{Vg}$ & 0.71 & 5.53 & 11.47 & 0.67 & 347.03 & 260.57 & 391.02 \\
$\mathrm{Vp}$ & 12.01 & 23.87 & 36.09 & 1.64 & 381.38 & 284.05 & 425.89 \\
$\mathrm{H}^{2}$ & 0.06 & 0.23 & 0.32 & 0.41 & 0.91 & 0.92 & 0.92 \\
Mean & 37.80 & 58.51 & 92.66 & 116.45 & 180.16 & 204.51 & 243.80 \\
Genetic Advance at 20\% & 0.29 & 1.58 & 2.67 & 0.73 & 24.88 & 21.64 & 26.53 \\
Genetic Advance as \% of Mean (20\%) & 0.76 & 2.71 & 2.89 & 0.63 & 13.81 & 10.58 & 10.88 \\
PCV (\%) & 9.17 & 8.35 & 6.48 & 1.10 & 10.84 & 8.24 & 8.46 \\
GCV (\%) & 2.22 & 4.02 & 3.66 & 0.70 & 10.34 & 7.89 & 8.11 \\
\hline
\end{tabular}

Note. $\mathrm{H}=$ Height, $\mathrm{MTHS}=$ Months, $\mathrm{Vg}=$ Genotypic variance, $\mathrm{Vp}=$ Phenotypic variance, $\mathrm{H}^{2}=$ broad sense heritability, GCV = genotypic coefficient of variation, $\mathrm{PCV}=$ phenotypic coefficient of variation.

\subsection{Genetic Component Analysis for Nut Yield}

Genotypic and Phenotypic variance estimates for yield fluctuated across the months (Table 8). High genotypic estimate was observed during the 2014 (Yld 2014) nut yield analysis while 2010 (Yld 2010) and 2013 (Yield 2013) recorded the least estimates.

Phenotypic variance estimates for nut yield were moderate, but highest in 2014 and lowest in 2009. Both genotypic and phenotypic variance for canopy span were relatively high. Broadsense heritability estimates for canopy span was high while that for nut yield were moderate and relatively stable across the months except in the case of year 2012 which recorded the highest estimate (0.84). Estimates for genetic advance at $20 \%$ selection intensity ranged from a low of 0.11 (Yld 2010; Yld 2013) to a high of 0.95 for canopy span. Phenotypic and genotypic co-efficient of variation for nut yield were similar in magnitude but considerably low for the canopy span. 
Table 8. Genetic analysis of average yields and canopy span of cashew accessions across Wenchi and Bole

\begin{tabular}{llllllll}
\hline \multirow{2}{*}{ Genetic components } & \multicolumn{7}{c}{ Nut Yield } \\
\cline { 2 - 8 } & Yld 2009 & Yld 2010 & Yld 2011 & Yld 2012 & Yld 2013 & Yld 2014 & Canopy size \\
\hline $\mathrm{Vg}$ & 0.10 & 0.04 & 0.10 & 0.25 & 0.04 & 0.29 & 0.72 \\
$\mathrm{Vp}$ & 0.11 & 0.24 & 0.13 & 0.29 & 0.24 & 0.62 & 1.09 \\
$\mathrm{H}^{2}$ & 0.48 & 0.17 & 0.48 & 0.84 & 0.17 & 0.47 & 0.65 \\
Mean & 1.70 & 2.52 & 3.08 & 3.20 & 4.22 & 3.43 & 32.58 \\
Genetic Advance at 20\% & 0.22 & 0.11 & 0.25 & 0.64 & 0.11 & 0.52 & 0.95 \\
Genetic Advance as \% of Mean (20\%) & 13.15 & 4.56 & 7.96 & 19.86 & 2.70 & 15.13 & 2.94 \\
PCV (\%) & 19.54 & 19.38 & 11.9 & 16.97 & 11.54 & 22.98 & 3.22 \\
GCV (\%) & 13.54 & 7.94 & 8.22 & 15.52 & 4.71 & 15.76 & 2.60 \\
\hline Note. Yld
\end{tabular}

Note. $\mathrm{Yld}=$ Yield, $\mathrm{Vg}=$ Genotypic variance, $\mathrm{Vp}=$ Phenotypic variance, $\mathrm{H}^{2}=$ broad sense heritability, $\mathrm{GCV}=$ genotypic coefficient of variation, $\mathrm{PCV}=$ phenotypic coefficient of variation.

\section{Discussions}

Information on the level of genetic variation and relationship among key agronomic traits of cashew is essential in identifying parental materials for yield improvement in plant breeding programs. The introduction of new germplasm increases the genetic variability among cashew collections and enhance breeding for trait improvement. In Ghana, limited cashew collections have been introduced over different period of time by the Non-governmental organizations (NGO), Missionaries and Research institutes. Among these introductions, only a few have been duly evaluated for adaptability, yield and other agronomic traits. In this study, the four dwarf cashew accessions and control were evaluated for genetic variation, yield and agronomic traits as well as relationship among traits. The study revealed varied performance among the accessions and control. The average girth increment (trunk size) among the accessions across 30 months revealed an initial slow growth (six to eighteen months) for all accessions planted in Wenchi compared to counterparts in Bole. This observation was quite unusual as environmental conditions in Wenchi have been reported as more conducive for cashew growth compared to Bole (Adu-Gyamfi et al., 2019). Despite the initial lag in Wenchi the growth trend for all accessions across locations within the first eighteen months were relatively similar and consistent with observations by Adewale et al. (2013) who reported trend analysis of cashew growth parameters and concluded that no differences exist in stem circumference expansion among cashew varieties during the juvenile growth phase.

Consequently, Hammed et al. (2011) reported that early growth of cashew varieties at the juvenile stage are often uniform except in situations where significant difference exist among the nut size of varieties used.

Obvious differences were noticed in the pattern and magnitude of girth increment after eighteen months across locations with the accessions in Wenchi relatively outgrowing that of Bole. This observation agrees in part with assertion that Wenchi environment is more favorable for cashew growth (Adu-Gyamfi et al., 2019). Differences in growth pattern and magnitude observed during the latter stage of the experiment reflects the relative sensitivity of genotypes to environmental effects, eighteen months after planting which implies that investigation on genotype by environment interactions $(\mathrm{G} \times \mathrm{E})$ in cashew could commence after 18 months of planting in the field. This interaction did not affect the ranking order in terms of two fast growing accessions (B2 and B5) across the locations and months. Such rapid growing accessions could serve as preferred rootstock for clonal propagation across multi environment since genotypes with rapid girth expansion turn to establish better than slow ones (Padi et al., 2012; Ofori et al., 2015). Rate of height increment within the 24 months after planting was relatively similar for all the accessions, including the control. However, the trend and magnitude of successive measurements changed for some accessions because of genotype by environment interactions. The consistency and rapid increment of height for accessions B2 and B5 suggested probable high meristematic activity within the apical buds when compared to the slow growth ones. Accession B3 and control (CRG C4) were identified as most sluggish for both girth and height growth and could therefore serve as candidates for breeding short cashew varieties.

Genetic analysis for all traits measured in this study indicated the presence of significant variation among the accessions tested. Although, the trial at Wenchi was laid out on a previously cultivated land, no significant differences were observed in block effect for most traits studied, which implied that the soil environment was less heterogeneous. Thus, the experiment was not influenced by previous cropping history. Furthermore, the experimental design used was suitable. Significant crop year observed for most traits suggest the need to further evaluate the traits for additional years, while the significant locational effect observed for most traits, especially, nut yield, is an indication of high variation between the contrasting locations (environments) which necessitates 
a further stability analysis to ascertain most stable accession for nut yield across environments. Furthermore, the significant genotype $\times$ location (environment) interaction effects observed for most of the measured traits showed that the selected environments were unique and that there was adequate genetic variability among the germplasm to permit genetic enhancement of the traits through location specific selection. This result is consistent with the findings of Adu-Gyamfi et al. (2019) who reported on genetic variability among cashew clones evaluated under two contrasting environments in Ghana. The authors further highlighted Wenchi's agro-ecology as more suitable for cashew cultivation. According to Comstock and Moll (1963) genotype $\times$ environment interactions determined in multi-locational trials reduces the correlation between genotypic and phenotypic values which are useful during selection among correlated traits. Hence the need to consider correlation estimates in conjunction with other estimates such as heritability and genetic advance which offers effective response to selection under contrasting environments.

Initial nut yields for all accessions except B3 were low at the onset of bearing but appreciated over time across the environments with trends of alternate bearing phenomenon, a common characteristic of most tree crops. The magnitude of alternate bearing was more profound in some accessions than others and may be attributed to the degree of genotypic response to environment. The alternate bearing nature (biannual bearing) which is characterized by alternation in high and low crop in successive seasons was evident irrespective of the level of nut yield recorded by a specific accession in a particular season. This trend continued over a four-year period of observation although, it was not evident in all consecutive years. Studies by Dennis (2003) indicated that high yields in a particular year tend to reduce the nutrient uptake necessary for flower, bud and fruit formation in the ensuing year. This phenomenon has been confirmed by Jackson (2003) who reported that hormones synthesized by seeds are usually transported from the developing ovules which may have a direct negative influence on subsequent flower development. This occurrence tend to affects both low and high yielding accessions or varieties equally, therefore, selection for preferred candidates in initial production years and progressing them would ensure the reproduction of only target genotypes which can be established in larger populations to enhance the ratio of desirable trees in the identification of suitable parents in breeding programs or clone development.

According to Austin (1993), yield is the best measure of integrated performance, profitability and overall adaptation provided it is estimated over several years. The fairly high yields recorded in Wenchi over Bole may be attributed to a probable adaptation of the accessions to a relatively favorable agro-ecology as reported in previous studies by Adu-Gyamfi et al. (2019). Such observation was not uncommon, as nut yield depends very much on several factors which included genotype, environment and a complex of genotype $\times$ environment factors (Magari \& Kang, 1993; Basford \& Cooper, 1998).

Austin (1993), further argued that cumulative yield which integrates a range of physiological characters and plant response to a changing environment as an efficient measure of plant performance during selection. This implies that effective selection could only be based on the cumulative performance but not the yearly fluctuations observed in this study as a result of environmental influence. In Bole (Guinea savanna zone), the cumulative nut yield showed that the performance of accession B2 was significantly different from that of B3. Meanwhile, the general plant performance based on the combined average cumulative nut yield, only ranked accessions B2 as the highest yielding genotype whilst accession B3 was the least since no significant $(\mathrm{p}<0.05)$ differences were observed among the accessions for nut yield. Canopy span which was measured six years after transplanting showed virtually no differences in size among the accessions, even though, some studies have reported significant differences because of genotypic influence.

Further studies on yield efficiency estimates which is an index that integrates yield with vegetative growth highlighted findings comparable to reports by Ofori et al. (2015) although, the magnitude here were relatively low. Yield efficiency estimates, have successfully been applied in tree crop improvement to compliment the identification and selection of efficient genotypes (Padi et al., 2012; Ofori et al., 2015; Akpertey et al., 2017). However, in this current study, not all accessions with high yield efficiency estimates were necessarily high yielding genotypes as observed in the performance of accession B3 which recorded the highest yield efficiency of $11.88 \mathrm{~kg} / \mathrm{ha} / \mathrm{cm}^{2}$ and the least cumulative average yield of $267.7 \mathrm{~kg} / \mathrm{ha}$ in the combined analysis. Such occurrence partly points to the fact that only a few accessions were evaluated.

Hitherto this investigation, trait correlations have largely been applied in selection programs to achieve correlated response to selection there by reducing cost and years of evaluation (Akpetey et al., 2017). Attempts made in assessing the relationship between early vegetative growth traits (girth, height, canopy span) and nut yield indicated positive correlations with varied magnitude of associations although, not significant. Similar observations were reported in trait association studies by Adu-Gyamfi et al. (2019) who highlighted a weak 
association between trunk cross-sectional area and yield in cashew clones evaluated in the Guinea savanna environment. The results implied that selection based on these secondary traits to complement nut yield may not be effective using this set of accessions. It is worthy to note that rapid height increment moderately correlated with nut yield, while in other studies such as cocoa, rapid girth increment at juvenile stage is a key pointer for selecting potentially high yielding genotypes. Such discrepancies of varied trait associated with yield are common in breeding programs when different set of germplasm materials or plant species were involved in separate studies (Badu Apraku et al., 2013; Dadzie, 2018). Based on information obtained from investigations made in this study especially, regarding the low magnitude of correlation coefficient of variation recorded for association between nut yield and other agronomic traits, it can be concluded that both girth and height are weak predictors of potentially high yielding cashew genotypes.

Genetic coefficient of variation (GCV) offers a measure to compare genetic variability in quantitative traits, whilst the phenotypic coefficient of variation provides information on the degree of environmental influence on traits. In this study, there was a close relationship between phenotypic and genotypic coefficient of variation for almost all the measured traits. This implies that transmissions of these characters are less affected by the environment. The coefficient of variation is more useful in comparing accessions since it is independent of the measuring units.

Highest genotypic and phenotypic coefficients of variation for nut yield were observed at the latter stage of the experiment whilst that of girth and height were moderate and relatively stable across seasons. Similar observations have been reported in upland cotton by Dheva and Potdukhe (2002), Preetha and Raveendran (2007), Amir et al. (2012), Abbas et al. (2013). The moderate PCV and GCV that were observed for girth and height increment were consistent with the reports by Girase and Mehatne (2002), Harshal (2010) in outturn studies of cotton. Such moderate phenotypic and genotypic coefficient of variation noticed for girth and height will require vigorous selection for improvement. Both GCV and PCV parameters together with heritability estimates determine the extent of heritable variation (Burton, 1951) in plant populations. Heritability values of the agronomic traits measured in this study at six monthly intervals for girth and height increment as well as yield displayed consistent seasonal variation in magnitude making it difficult to select nor predict genetic advance for trait improvement based on estimates from only one particular season. Akpertey et al. (2017) confirmed seasonal inconsistencies in heritability estimates among kola progeny trials and suggested the use of average cumulative variances in the estimation of heritability.

On the contrary the seasonal estimates observed in this study revealed some level of consistency in the magnitude of heritability estimates among the traits especially, yield during the later stages of the evaluation and may be useful during selection. According to Ahsan et al. (2015), broad sense heritability estimates alone could not be useful for trait selection since it does not provide an idea about the expected gains in the subsequent generation, but vital when considered in conjunction with genetic advance estimates. Traits that exhibit high heritability as well as maximum genetic advance as percentage of mean may be used in selection because such traits are controlled mainly by additive genes with minimal environmental influence (Panes \& Sukhatme, 1995). The broad sense heritability and genetic advance as a percentage of mean were highest and effective for selection during the twenty-fourth month for girth, thirtieth month for height and nut yield for year 2012 respectively. Meanwhile selection for canopy span may not be very effective although it recorded high heritability of 0.65 but low mean genetic advance with low PCV and GCV similar to the findings of Nyadanu and Dikera (2014). In such situations, selection of accessions for further breeding may depend solely on the genotypic performance.

Generally, some accessions in this experiment have been identified as potential donors of favorable alleles for cashew improvement of different traits. According to results obtained from this study, we can conclude that direct selection could be applied for nut yield once it exhibited high genetic variability in specific environment coupled with high range of variation.

Furthermore, the low variation in canopy span means that plant tree architecture will not be affected when the accessions are utilized in future breeding.

\section{Conclusion}

The authors report here of significant genetic variation among the four cashew accessions evaluated. This would be useful for trait improvement in the cashew breeding program. Environmental influence was found to be significant on genotypic performance. However, nut yields of the accessions were variable across the environments and also displayed alternate bearing phenomenon. Furthermore, early growth pattern of girth and height were inadequate to predict late performance of cashew accessions as reported in other crops. Finally, no significant relationship was observed between nut yields and other agronomic traits such as girth and height 
increment as well as canopy and that these traits may not be reliable to complement nut yield in this set of accessions evaluated.

\section{Acknowledgements}

The authors wish to thank Messrs. Dapla Fred and Bambai Marcelanous, of the Bole and Wenchi research stations for technical assistance. We also want to thank all staff and the Technical staff of the Plant Breeding Division, CRIG for their support and assistance. The authors wish to thank World Bank and African Development Bank who provided funding through the cashew development project at the Ministry of Food and Agriculture. This paper is published with kind permission of the Executive Director of Cocoa Research Institute of Ghana (CRIG) as manuscript number CRIG/02/2020/033/08.

\section{References}

Abbas, H. G., Mahmood, A., \& Ali, Q. (2013). Genetic variability, heritability, genetic advance and correlation studies in cotton (Gossypium hirsutum L.). International Research Journal of Microbiology, 4, 156-161.

Adeigbe, O. O., Olasupo, F., Adewale, B. D., \& Muyiwa, A. A. (2015). A review of cashew research and production in Nigeria in the last four decades. Scientific Research Essays, 10, 196-209. https://doi.org/ 10.5897/SRE2014.5953

Adewale, B. D., Ibiremo, O. S., Odoh, N. C., \& Adeyemi, E. A. (2013). Genetic estimates and trend analysis of some growth parameters of cashew (Anacardium occidentale L.) as influenced by nine nutrient combinations. Journal of Agricultural Biotechnology and Sustainable Development, 5, 6-11. https://doi.org/ 10.5897/JABSD12.035

Adomako, B., \& Adu-Ampomah, Y. (2005). Assessment of the yield of individual cacao trees in four field trials. Proceedings of the International Workshop on Cocoa Breeding for Improved Production Systems, Accra, Ghana, October 19-21, 2003 (pp. 41-49).

Adu-Gyamfi, P. K. K., Dadzie, M. A., Barnor, M., Akpertey, A., Arthur, A., Osei-Akoto, S., \& Padi, F. (2019). Genetic variability and trait association studies in cashew (Anacardium occidentale L.). Scientia Horticulturae, 255, 108-114. https://doi.org/10.1016/j.scienta.2019.05.023

Ahsan, M. Z., Majidano, S., Bhutto, B. H., Soomro, A. W., Panhwar, F. H., Channa, A. R., \& Sial, K. B. (2015). Genetic Variability, Coefficient of Variance, Heritability and Genetic Advance of Some Gossypium hirsutum L. Accessions. Journal of Agricultural Science, 7(2), 147. https://doi.org/10.5539/jas.v7n2p147

Akpertey, A., Dadzie, A. M., Adu-Gyamfi, P. K. K., Ofori, A., \& Padi, F. K. (2017). Effectiveness of juvenile traits as selection criteria for yield efficiency in kola. Sci. Hortic., 216, 264-271. https://doi.org/10.1016/ j.scienta.2017.01.018

Aliyu, O. M., \& Awopetu, J. A. (2005). In-vitro regeneration of hybrid plantlets of cashew (Anacardium occidentale L.) through embryo culture. African Journal of Biotechnology, 4, 548-553.

Aliyu, O. M., \& Awopetu, J. A. (2007). Chromosome studies in cashew (Anacardium occidentale L.). African Journal of Biotechnology, 6, 131-136. Retrieved from http://www.academicjournals.org/AJB

Amir, S., Farooq, J., Bibi, A., Khan, S. H., \& Saleem, M. F. (2012). Genetic studies of earliness in Gossypium hirsutum L. IJAVMS, 6, 189-207. https://doi.org/10.5455/ijavms.153

Austin, R. B. (1993). Augmenting yield-based selection. In M. D. Hayward, N. O. Bosemark, \& I. Romagosa (Eds.), Plant Breeding, Principles and Prospects (pp. 391-405). Chapman \& Hall. https://doi.org/ 10.1007/978-94-011-1524-7_24

Badu-Apraku, B., Oyekunle, M., Akinwale, R. O., \& Aderounmu, M. (2013). Combining ability and genetic diversity of extra-early white maize inbreds under stress and non-stress environments. Crop Science, 53, 9-26. https://doi.org/10.2135/cropsci2012.06.0381

Basford, K. E., \& Cooper, M. (1998). Genotype x environment interactions and some considerations of their implications for wheat breeding in Australia. Australian Journal of Agricultural Research, 49, 154-174. https://doi.org/10.1071/A97035

Buadi, D. K., Anaman, K. A., \& Kwarteng, J. A. (2013). Farmers' perceptions of the quality of extension services provided by non-governmental organisations in two municipalities in the Central Region of Ghana. Agricultural Systems, 120, 20-26. https://doi.org/10.1016/j.agsy.2013.05.002 
Burton, G. W. (1951). Quantitative inheritance in pearl millet (Pennisetum glaucum). Agronomy Journal, 43, 409-417. https://doi.org/10.2134/agronj1951.00021962004300090001x

Comstock, R. E., \& Moll, R. H. (1963). Genotype-environment interactions. In W. D. Hanson \& H. F. Robinson (Eds.), Statistical Genetics in Plant Breeding (pp. 164-194). NAS-NRC Publ. 982, Washington, D.C.

Dadzie, A. M., Adu-Gyamfi, P. K. K., Opoku, S. Y., Yeboah, J., Akpertey, A., Opoku-Ameyaw, K., ... Danquah, W. B. (2014). Evaluation of potential cashew clones for utilization in Ghana. Adv. Biol. Chem., 4, $232-239$. https://doi.org/10.4236/abc.2014.44028

Dadzie, M. A. (2018). Breeding maize (Zea mays L.) for resistance to aflatoxin accumulation in Ghana (PhD Thesis, University of Ghana Legon, West Africa Centre for Crop Improvement/School of Agriculture/ College of Agriculture and Consumer Sciences).

Dendena, B., \& Corsi, S. (2014). Cashew, from seed to market: a review. Agron. Sustain. Dev., 34, $753-772$. https://doi.org/10.1007/s13593-014-0240-7

Dennis, F. Jr. (2003). Flowering, pollination and fruit set and development. In D. C. Ferree, \& I. J. Warrington (Eds.), Apples: Botany, Production and Uses (pp. 153-166). CABI Publishing, Cambridge, MA. https://doi.org/10.1079/9780851995922.0153

Dheva, N. G., \& Potdukhe, N. R. (2002). Studies on variability and correlations in upland cotton for yield and its components. J. Indian Soc. Cotton Improv., 148-152. https://doi.org/10.5958/0975-928X.2017.00024.2

Falconer, D. S. (1989). Introduction to Quantitative Genetics (3rd ed.). Logman Scientific and Technical, Logman House, Burnt Mill, Harlow, Essex, England.

FAO-UNESCO. (1977). Soil Maps of the World: 1:50,000,000 Africa 6 (p. 299). UNESCO, Paris.

GEPA. (2018). Cashew Export. Retrieved May 30, 2018, from https://www.gepaghana.org/market-report/ cashew-nut-shell-competitor-analysis-2017

Girase, V. S., \& Mehetre, S. S. (2002). Correlation and path analysis of cotton-A review. J. Cotton Res. Dev., $16,8-12$.

Hammed, L. A., Lawal, B. A., \& Kolapo, K. A. (2011). Growth and nutrient uptake of cashew (Anacardium occidentale L.) Seedlings as affected by nutsize in the nursery. Afr. J. Agric. Res., 6, 3962-3971.

Harshal, E. P. (2010). Variability and correlation analysis by using various quantitative traits in released Bt cotton hybrids. J. Cotton Res. Dev., 24, 141-144. https://doi.org/10.5897/AJPS2013.1099

Jackson, J. E. (2003). Flowers and fruits. Biology of Apples and Pears (pp. 268-308). Cambridge University Press, New York. https://doi.org/10.1017/CBO9780511542657.011

Johnson, H. W., Robinson, H. F., \& Comstock, R. E. (1955). Estimates of genetic and environmental variability in soyabeans. Agron. J., 47, 314-318. https://doi.org/10.2134/agronj1955.00021962004700070009x

Magari, R., \& Kang, M. S. (1993). Genotype selection via a new yield-stability statistics in maize yield trials. Euphytica, 70, 105-111. https://doi.org/10.1007/BF00029647

Masawe, P., Cundall, E., \& Caligari, P. (1999). Studies on genotype-environment interaction (G×E) in half-sib progenies of cashew (Anacardium occidentale L.) in Tanzania. Tanzania J. Agric. Sci., 2.

Nyadanu, D., \& Dikera, E. (2014). Exploring variation: relationships and heritability oftraits among selected accessions of sorghum (Sorghum bicolor L. Moench) in the Upper East Region of Ghana. J. Plant Breed. Genetics, 2, 101-107.

Ofori, A., Padi, F. K., Acheampong, K., \& Lowor, S. T. (2015). Genetic variation and relationship of traits related to drought tolerance in cocoa (Theobroma cacao L.) under shade and no-shade conditions in Ghana. Euphytica, 201, 411-421. https://doi.org/10.1007/s10681-014-1228-8

Oluyemisi, L. E., \& Uwagboe, E. O. (2017). Cost effectiveness of intercropping patterns by cashew farmers in Oyo State, Nigeria. Int J. Forest Animal Fish Res., 1, 27-30.

Opoku-Ameyaw, K, Oppong, F. K., Amoah, F. M., Osei-Akoto, S., \& Swatson, E. (2011). Growth and early yield of cashew intercropped with food crops in northern Ghana. J. Trop Agric., 49, 53-57.

Osei-Akoto, S. (2010). A Value Chain Analysis of the Cashew Sector in Ghana. African Cashew Initiative (p. 13). Deutsche Gesellschaft für Technische Zusammenarbeit (GTZ) GmbH, Germany. 
Osei-Amaning, E. (1996). Managing of Vitellaraia paradoxa in Ghana (Ph.D. Thesis, University of Wales, Bangor).

Padi, F. K., Opoku, S. Y., Adomako, B., \& Adu-Ampomah, Y. (2012). Effectiveness of juvenile tree growth rate as an index for selecting high yielding cocoa families. Sci. Hort., 139, 14-20. https://doi.org/ $10.1080 / 15427528.2013 .768319$

Panes, V. G., \& Sukhatme, P. V. (1995). Statistical methods for agricultural workers (3rd ed., p. 58). ICAR, New Delhi.

Preetha, S., \& Raveendran, T. S. (2007). Genetic variability and association studies in three different morphological groups of cotton (Gossypium hirsutum L.). Asian J. Plant Sci., 6, 122-128. https://doi.org/ 10.3923/ajps.2007.122.128

Robinson, H. F., Comstock, R. E., \& Harvey, P. H. (1949). Estimatesof heritability and degree of dominance in corn. Agronomy J., 41, 253-259. https://doi.org/10.2134/agronj1949.00021962004100080005x

Sivasubramanian, S., \& Menon, M. (1973). Heterosis and inbreeding depression in rice. Madras Agric. J., 60, 1139.

Sys, C., \& Van Ranst, E. (1993). Land Evaluation Part 3: Crop Requirements Agricultural Publications No. 7. GADC, Brussels, Belgium.

Wongnaa, C. A., \& Awunyo, V. (2013). Analysis of Factors Affecting the Production of Cashew in Wenchi Municipality, Ghana. The Journal of Agricultural Sciences, 8, 8-16. https://doi.org/10.4038/jas.v8i1.5377

\section{Copyrights}

Copyright for this article is retained by the author(s), with first publication rights granted to the journal.

This is an open-access article distributed under the terms and conditions of the Creative Commons Attribution license (http://creativecommons.org/licenses/by/4.0/). 